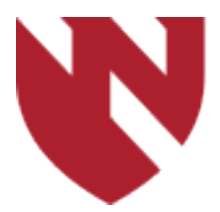

September 2020

\title{
Establishing an Institution-Wide Graduate Medical Education Research Collaborative to Promote Scholarly Activities among House Officers
}

\author{
Kaeli K. Samson \\ University of Nebraska Medical Center \\ Lynette M. Smith \\ University of Nebraska Medical Center \\ Valerie Shostrom \\ University of Nebraska Medical Center \\ Jeffrey P. Gold \\ University of Nebraska Medical Center \\ Chandrakanth Are \\ University of Nebraska Medical Center
}

Tell us how you used this information in this short survey.

Follow this and additional works at: https://digitalcommons.unmc.edu/gmerj

Part of the Higher Education Commons, and the Medical Education Commons

\section{Recommended Citation}

Samson, K. K., Smith, L. M., Shostrom, V., Gold, J. P., , Are, C. Establishing an Institution-Wide Graduate Medical Education Research Collaborative to Promote Scholarly Activities among House Officers. Graduate Medical Education Research Journal. 2020 Sep 29; 2(1).

https://digitalcommons.unmc.edu/gmerj/vol2/iss1/7

This Original Report is brought to you for free and open access by DigitalCommons@UNMC. It has been accepted for inclusion in Graduate Medical Education Research Journal by an authorized editor of DigitalCommons@UNMC. For more information, please contact digitalcommons@unmc.edu. 


\title{
Establishing an Institution-Wide Graduate Medical Education Research Collaborative to Promote Scholarly Activities among House Officers
}

\author{
Abstract \\ Background: House officers' ability to participate in research and quality improvement projects can be \\ hindered by barriers, including lack of time, mentoring, and resources. \\ Objective: Create a collaborative for house officers that provides readily accessible resources in study \\ design as well as data collection, analysis, interpretation, and presentation.
}

Methods: In 2017, we established a collaborative comprised of biostatisticians and an Associate Dean for Graduate Medical Research, providing a trove of experience in research and quality improvement. We worked closely with the Institutional Review Board and Electronic Health Records Core to simplify the process for house officers to utilize these research resources. The collaborative has weekly small group meetings to discuss new projects/updates and monthly large group meetings where house officers can present their ideas for additional feedback from peers and additional faculty. These formats are flexible, which allows us to tailor our assistance to the needs of each individual project.

Results: In the first year since establishing the collaborative, we have received 51 project concepts from 44 house officers. Of the projects needing assistance $(n=44), 100 \%$ were discussed in one of our weekly meetings and received assistance from the collaborative, and $34 \%$ presented at our large monthly meeting. A year into the collaborative, $20 \%$ of projects are either in the data analysis phase or have already been presented.

Conclusion: As evidenced by the number of projects we received in our first year, there is a significant benefit for this type of collaborative resource to support and stimulate successful scholarly activity in house officers.

\section{Keywords}

Scholarly Activity, Resident Research, Collaborative

\section{Creative Commons License}

\section{c) (i) $\Theta$}

This work is licensed under a Creative Commons Attribution-Noncommercial-No Derivative Works 4.0 License.

\section{Cover Page Footnote}

Acknowledgements: Funding for the Collaborative is provided through the University of Nebraska Medical Center's (UNMC's) Dean's Office of the College of Medicine. Research Electronic Data Capture (REDCap) at UNMC is supported by the Research IT Office funded by the Vice Chancellor for Research (VCR) and receives partial support from the Great Plains IDeA-CTR grant. This publication's contents are the sole responsibility of the authors and do not necessarily represent the official views of the VCR and NIH. Abbreviations: CLER: Clinical Learning Environment Review; EHR: Electronic Health Records; GMERC: Graduate Medical Education Research Collaborative; IRB: Institutional Review Board; REDCap: Research Electronic Data Capture; UNMC: University of Nebraska Medical Center 


\section{Establishing an Institution-Wide Graduate Medical Education Research Collaborative to Promote Scholarly Activities Among House Officers}

Kaeli K. Samson', Lynette M. Smith', Valerie Shostrom¹, Jeffrey P. Gold², Chandrakanth Are ${ }^{3}$

${ }^{1}$ University of Nebraska Medical Center, College of Public Health, Department of Biostatistics

${ }^{2}$ University of Nebraska Medical Center, Office of the Chancellor

${ }^{3}$ University of Nebraska Medical Center, Office of Graduate Medical Education

\begin{abstract}
Background: House officers' ability to participate in research and quality improvement projects can be hindered by barriers, including lack of time, mentoring, and resources.
\end{abstract}

Objective: Create a collaborative for house officers that provides readily accessible resources in study design as well as data collection, analysis, interpretation, and presentation.

Methods: In 2017, we established a collaborative comprised of biostatisticians and an Associate Dean for Graduate Medical Research, providing a trove of experience in research and quality improvement. We worked closely with the Institutional Review Board and Electronic Health Records Core to simplify the process for house officers to utilize these research resources. The collaborative has weekly small group meetings to discuss new projects/updates and monthly large group meetings where house officers can present their ideas for additional feedback from peers and additional faculty. These formats are flexible, which allows us to tailor our assistance to the needs of each individual project.

Results: In the first year since establishing the collaborative, we have received 51 project concepts from 44 house officers. Of the projects needing assistance $(n=44), 100 \%$ were discussed in one of our weekly meetings and received assistance from the collaborative, and $34 \%$ presented at our large monthly meeting. A year into the collaborative, $20 \%$ of projects are either in the data analysis phase or have already been presented.

Conclusion: As evidenced by the number of projects we received in our first year, there is a significant benefit for this type of collaborative resource to support and stimulate successful scholarly activity in house officers.

\section{Introduction}

An important aspect in the education of house officers is providing opportunities to participate in research encompassing the areas of patient safety, quality improvement, health disparities, and many others, which can potentially lead to presentations or publications. ${ }^{1,2}$ However, the ability to conduct research can be stifled by the lack of access to resources or the necessary research infrastructure. The aim of this report is to review our experience of starting an institution-wide Graduate Medical Education Research Collaborative (GMERC) to promote these scholarly activities at our campus consisting of nearly 61 training programs and 530 house officers.

\section{Methods}

The GMERC was created in 2017 and consists of four key members that include the Associate Dean for GME, a PhD biostatistician, and two master's level biostatisticians. The four members have strong backgrounds in research, with particular emphasis on patient safety/quality improvement and disparities projects. The GMERC provides house officers with assistance in the following areas: brainstorming patient safety and quality improvement/research concepts, discussing methodology, study design, applying for and attaining Institutional Review Board (IRB) approval, data acquisition, statistical analysis, abstract preparation, and manuscript preparation for publication.

Project Initiation/Tracking: House officers are encouraged to submit their research idea through Research Electronic Data Capture (REDCap), ${ }^{3}$ a secure, web-based application hosted at the University of Nebraska Medical Center (UNMC), which notifies GMERC staff of new submissions. The house officer is then invited to present their research concept at a weekly meeting.

Weekly Meetings: All GMERC members attend weekly informal meetings, in addition to the presenting house officers. House officers present their research idea and are given comprehensive feedback regarding how to initiate, improve, and complete their projects. Residents are encouraged to attend as many meetings as needed as they move along the research continuum in order to receive guidance, encouragement, and assistance with all phases of their research.

\begin{abstract}
Monthly Meetings: Once a month, the GMERC hosts a larger meeting, which is attended by additional personnel, including faculty experts in patient safety/ quality improvement, representatives from the quality division of our hospital partner, representatives from the IRB, and several other entities involved with quality improvement on our campus, including other house officers. This provides another opportunity for house officers to present their ideas and receive feedback. Additionally, the resident's peers, who attend these meetings, may also develop their own research ideas and collaborations.
\end{abstract}

Affiliations: There are two important affiliates with whom the GMERC regularly interacts: the IRB and the Electronic Health Records (EHR) core. The collaborative serves as an intermediary between the house officers and the IRB, in order to aid in the process of initiating and obtaining IRB approval. The GMERC works with the EHR core to obtain data from our hospital partner's EHR for research projects. See Figure 1 on next page for a diagram of the GMERC composition and affiliations as they relate to the research process.

\section{Project management: The GMERC maintains a log of all projects, including timelines, engagement with the collaborative, and communications. This log is reviewed monthly by the GMERC to ensure that the projects are steadily progressing with appropriate reminders sent as needed.}

UNMC's IRB does not consider this program overview to constitute human subjects research.

\section{Results}

In the first year since the initiation of the GMERC, we received 51 project concepts submitted by 44 house officers. Seven projects had already been completed when they were submitted, and thus did not require assistance, but the remaining 44 projects have been discussed in person during at least one weekly meeting. Fifteen projects have been presented by the house officer who initiated the project at a larger monthly meeting to receive additional feedback. 

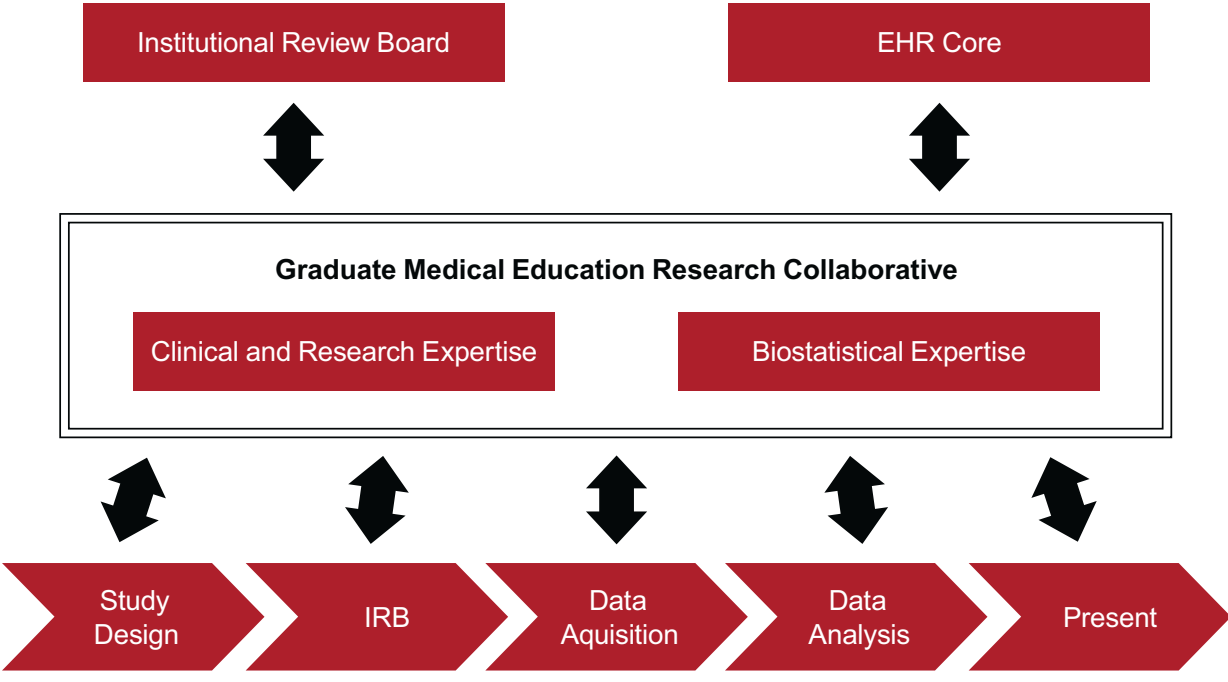

Figure 1. Schematic of structure of the Graduate Medical Education Research Collaborative. The large, middle box represents the core collaborative group. Boxes above are close affiliates of the collaborative. Boxes below indicate stages of the research process; house officers can utilize resources from the collaborative at all stages of the research process.

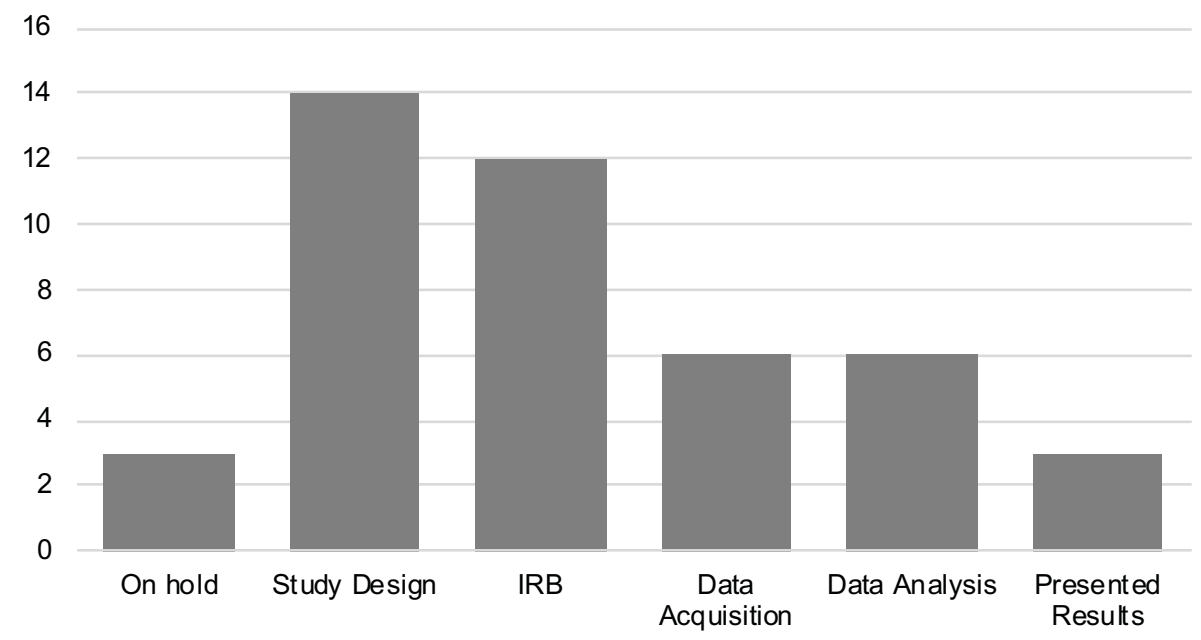

Figure 2. Distributions of GMERC projects needing assistance by research stage $(n=44)$. 'On Hold' represents projects from house officers that submitted more than one project and we decided to place one (or more) project(s) on hold while focusing efforts on the active project; 'Study Design' also includes survey design for projects that include questionnaire development; 'IRB' is for drafting IRB applications appropriate for the study, including sample size calculations and statistical methodology; 'Data Acquisition' could mean survey distribution, manual data collection through patient records, and/or EHR core data pulls; 'Data Analysis' includes any statistical analyses needed for projects, performed by the statisticians in the collaborative; 'Presented Results' includes presentation to hospital leaders (e.g. QI projects), local or national conferences, or manuscripts.

\section{Discussion}

At the GMERC's first year anniversary, it is clear that there is a need for these types of resources. Although the projects discussed in this paper are not inclusive of all the house officer-led research projects currently underway on our campus, the number of requests we received in the first year demonstrates there was a gap in research resources (or awareness of resources), which engaged the resources of the collaborative. These 44 projects are not just connected to the house officers that originally proposed the project, as many of these projects have multiple house officers working on them. The collaborative encourages house officers to find more junior house officers to join their project as a way to get others engaged in the collaborative, as well as to have someone to pass the project off to when the more senior officer completes their program.
In addition to the progress that has been made on the current projects in our collaborative, another measure of success for the GMERC was the high attendance for our inaugural annual GME Symposium, which showcased house-officer led research and quality improvement projects. In addition, the research collaborative received favorable feedback from our house officers during our most recent Clinical Learning Environment Review (CLER) visit.

One of the limitations of this study is that it only reflects the experience of a single institution, and may not generalize to other institutions. In addition, it is too early to say how many of these projects will ultimately advance to the presentation/publication phase. The process of initiating a research collaborative also has a number of challenges. The first is not only funding, but time that must be allocated for faculty and staff to work as part of the collaborative. It is time intensive to arrange and attend meetings, maintain communication, and assist on projects, and without reserved time from members of the collaborative, we would not have had the success we have seen thus far. In addition, despite providing a wealth of assistance for house officers working on projects and communicating widely about our existence, there are still house officers, faculty, and program directors who are unaware of this valuable resource.

\section{Conclusion}

Offering assistance and guidance in the research process is valuable to all house officers, particularly those who come from smaller programs which may lack these types of supportive resources. The GMERC serves to remove barriers house officers face when conducting research and quality improvement projects, to increase their participation in quality improvement, health disparities, and a wide spectrum of research projects.

https://doi.org/10.32873/unmc.dc.gmerj.2.1.002

\section{References:}

1 Accreditation Council for Graduate Medical Education. Common Program Requirements. https://www.acgme.org/Portals/0/PFAssets/ ProgramRequirements/CPRs_2017-07-01.pdf Accessed 12/13/2018.

2 Accreditation Council for Graduate Medical Education. Clinical Learning Environment Review. https://www.acgme.org/What-We-Do/Initiatives/ Clinical-Learning-Environment-Review-CLER. Accessed 12/13/2018.

3 Harris PA, Taylor R, Thielke R, et al. Research electronic data capture (REDCap) - a metadata-driven methodology and workflow process for providing translational research informatics support. Journal of biomedical informatics. 2009; 42.2: 377-381. 